\title{
HOM ENAGE;M
}

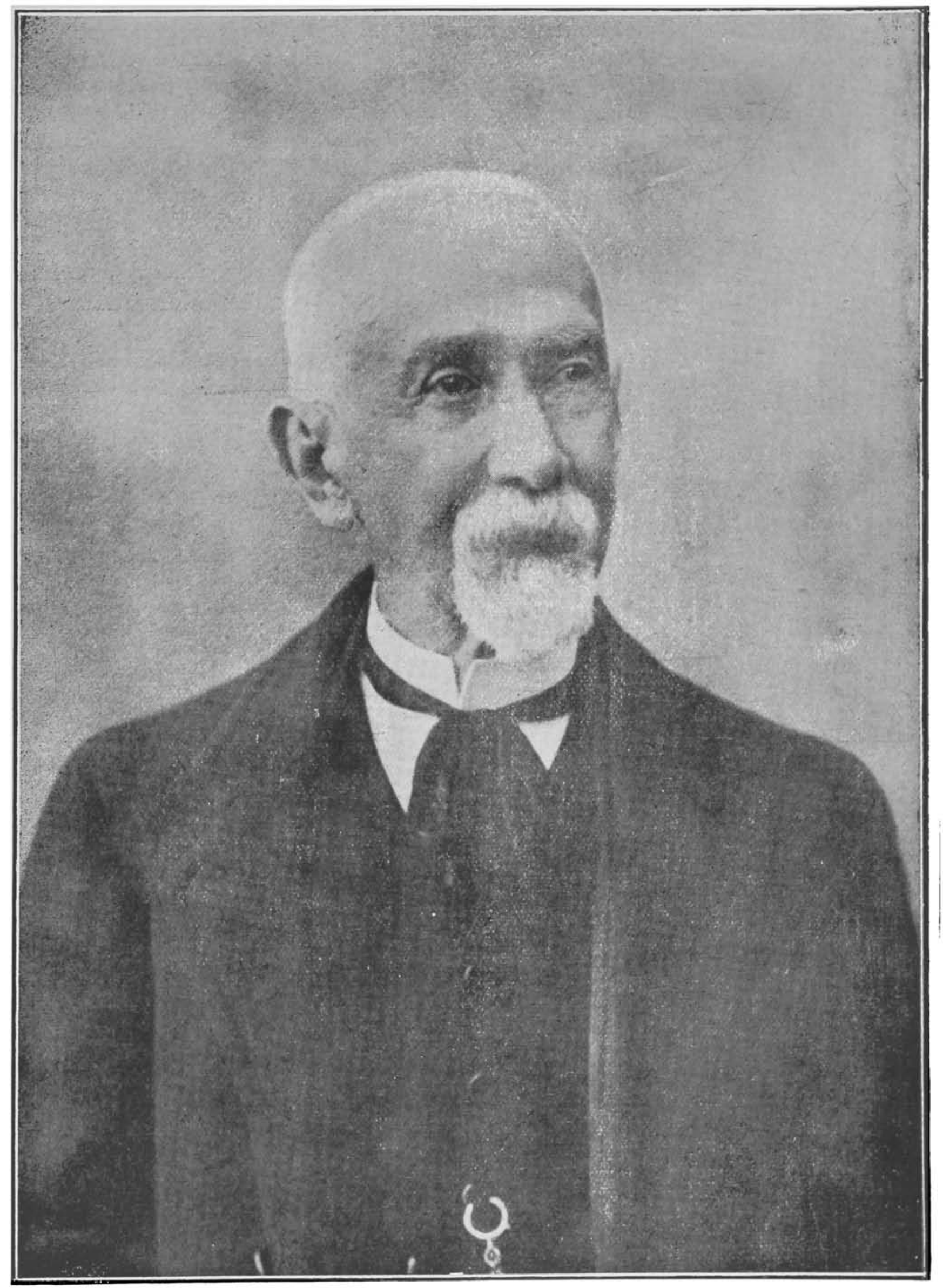

DR. LUIZ PEREIRA BARRETO, Mestre de nós todos e sabio entre os Mestres, 1 "Revista de Medicina" 

veridade da lesão, como tambem no tempo necessario para a cura completa dos animaes.

Alguns scientistas, tendo por base a marcha clinica, a cronicidade das lesões e a porcentagem das localisações nas mucosas affirmam que :s nossa Leismmaniose é differente da Oriental.

(Continua)

\section{LUIZ PEREIRA BARRETTO \\ PELO \\ DR. EMILIO RIBAS}

A vida do dr. Luiz Pereira Barretto se resume sobretudo nas manifestações do seu talento, do seu patriotismo e bondade.

Além dos de ordem medica, os assumptos de alta revelancia social têm recebido sempre o influxo do seu saber e, no caso particular de S. Paulo, todos conhecem que elle tem voltado as suas vistas de scientista e observador emerito para os interessantes problemas agricolas e de pecuaria, procurando facilitar o desenvolvimento destes factores maximos da nossa riqueza.

Comprehendendo, porém, que o progresso, para ser completo, precisa de um povo forte e que habite em regiões salubres, o dr. Barretto vem prestando ha muitos annos o seu intelligente concurso para a solução de vitaes problemas de hygiene social.

E, si o seu talento tem triumphado por vezes em outros terrenos, năo são menos admiraveis os seus serviços em pról da salubridade do nosso paiz.

O typho americano, originario do Novo Mundo, teve os seus principaes fócos, desde época remota, no Golfo do Mexico, Antilhas e America Central, irradiando-se destes pontos, geographicamnete estrategicos; para fragellar os outros paizes das duas Americas.

Em consequencias de enormes devastações deste flagello, contam os historiadores que na trceira expedição de Colombo, á que adheriram os homens livres, pelo terror que inspirava a despovoadora peste, teve o governo hespanhol necessidade, por fim de fundar as primeiras colonias, de lançar mão dos condemnados, promettendo-lhes a liberdade. 
Este facto e muitos outros, posteriormente conhecidos, demonstram claramente que a febre amarella fui, atravez dos secuios, o maior esiorvo au progiesso das naçöes americanas.

O nosso Brasil victimado por diversas vezes em remotos tempos, foi ultimamente flagellado durante mais de meio seculo e tăo frofundamente se assignalou a má fama de paiz insalubre, de terra inhabitavel, que o extrangeiro vacillou em crer na nossa transformação sanitaria, que houvessemos emfim vencido o inimigo capital do nosso prgoresso.

E' assim que, depois da extincção da febre amarella nos nossos principaes portos e cidades do interior, um jornalista allemão procurou em Berlim o exmo. sr. conselheiro Rodrigues Alves, derlarando-lhe que havia receb:do um artigo sobre as boas condições de salubridade do Brasil, mas que só o publicaria depois de ter o testemunho de s. excia., que acabava de ser o presidente da Republica Brasileira e cuja palavra de modo algum poderia ser posta em duvida.

$\mathrm{O}$ exmo. sr. conselheiro Rodrigues Alves, a quem se deve o maior impulso governamental para a benefica transformaçào sanitaria do Brasil, tinha todos os elementos para aftirmar que as conclusões do artigo eram, de facto, verdadeiras e, assim, foram ellas publicadas naquella capital.

Tive tambem opportunidade de verificar em Londres, quasi na mesma época, essa incredulidade a respeito da nossa saude publica.

Attendendo a convite da Sociedade de Medicina e Hygiene Tropicaes, com séde naquella capital, para tomar parte na sessão de 19 de Feverei:o de 1909, presidida pelo nctavel professor sir Patrick Manson e na qual se t:atou exclusivamente da fobre amarelia, li um trabaiho sobre a extincção Cessa molestia no Estado de S. Paulo e na cidade do Rio de Janeiro, fazendo-o acompanhar de projecções e diagrammas, para provar com maior evidencia as nossas excellentes condições de salubridade.

Esteve presente a esta sessão o distincto medico inglez dr. William London Strain, clinico em S. Paulo durante 17 annos, que muito trabalhou nas teriveis epidemias de febre amarella de Santos, mas que foi tambem testemunha da nossa transformação sanitaria e que citou mesmo perante essa douta Sociedade o interessante facto de ser aquella cidade procurada hoje como estação climaterica.

Terminada a sessão, o dr. Strain disse-me que as communicações no sentido da que eu acabava de apresentar, eram de inteira opportunodale $\dot{e}$ muito necessaria aos creditos de salubridade do Brasil, porque, apesar da extinç̧ão da febre amarella no nosso paiz, tornava-se no momento muito util uma propaganda systematica com o fim de provar os reaes effeitos praticos de prophylaxia scientifica, e, continuando fez esta comparação: Os rrandes desastres por esta molestia foram em tal numero e durante tão lnogo tempo, que se dizer, aqui, ao nosso povo que o Brasil está livre da febre amarella, the causa a mesma estranheza que quando se 
The communica que um individuo cheio de vicios e sempre bohemio se regeneron, sendo agora cumpridor de deveres - uma pessoa enfim muito séria."

E' que no espaço de tempo lecorrido da extinç̧ác do má, aııe por tão longos annos nos infelicitou, näo era ainda sufficiente para fazer esquecer a dolorosa hecatombe do cruzador italiano "Lombardia" cuja tripulação foi inteiramente dizimada pela febre amarella no porto do Rio de Janeiro, tendo tambem as de outros vapores, que tiveram de regressar de Santos e do Rio conduzidos por pessoal contractado, soffrido grandies devastações.,

Ainda não era tambem tempo de sẹ apagar a pencsa impressão causada por esta molestia ao victimar diplomatas extrangeirus e artistas celebres que procurvaam o nosso paiz; ainda se conservava a triste lembranca das grandes hecatombes produzidas pelo mortifero mal entre os immigrádos para os trabalhos da nossa lavoura; perdurava, por certo, ainda a in pressionante scena dos cadaveres insepuitos em Campinas, por haver a grande mortalidade de certo dia vencido os coveiros pelo cançaço.

Foi deante destes dolorosos quadros que o illustre dr. Luiz Pereira Barretto collocou todo seu brilhante talento e patriotismo a serviço da solução do magno problema da nossa regeneração sanitaria. E ninguem melhor do que elle exprimiu em linguagem tão sincera quanto elegante a necessidade de estudos conducentes a essa solução, quando ha muitos annos escreveu: "Na questão da febre amarella em Campinas, não está em jogo unicamente a vida de uma grande cidade: essa população que se afunda e desapparece, muda e fria nas covas do cemiterio, arrasta consigo em uma só mortaiha a honra e o futuro da provincia inteira.

A cada golpe de pá ouve-se o éco, que reteumba medonhamente no exterior, apavorando a immigração, anniquilando os nosos creditos de paiz habitavel, de povo civilizado.

A resurreição de Campinas impõe-se como um dever elementar, como am ponto de honra suprema."

E mais modernamente no seu interessante trabalho intitulado - "A iogica como instrumento de pesquiza no estudo da epidemiologia" e apresentado ha 14 annos á nossa Sociedade de Medicina e Cirurgia, o dr. Barretto assim se exprime: Ha 12 annos que a febre amarella, "sicut leo quærens devoret", grassa em S. Paulo, acastellando-se ora em um povoado, ora em outro, comprazendo-se por vezes em investir contra pequeos grupos de casas á margem das linhas ferreas. invadindo mesmo, algumas vezes, como por diversão, algumas colonos nas fazendas, sempre polvilhando de tumulos a superficie do Estado, quando não amontoa pavorosas hecatombes como em Campinas e Sorocaba. 
Doze annos de flagello não serão tempo sufficiente para cada um de nós depois de obsenvar detidamente a marcha invraiavel da epidemia em cada lugar, recolher-se em meditação e formular uma opinião sobre o seu modo de propagação?"

Obesrvador emerito, o dr. Barretto não acreditava nas theorias dos rnestres de hygiene que pretendiam exploar a disseminação da molestia, e o seu espirito esclarecido estava tão preparado para acceitar as conclusões dos estudos feitos em Cuba pela commissão que tinha por chefe Walter Read e que considerou a "stegomyia fasciata" como o unico agente provado na propaganda do mal.

Nesse tempo, porém, surgiram no nosso paiz obejecções que pareciam fundadas, por parte de profissonaes honestos e competentes, alguns até professores das nossas Faculdades de Medicina, que, partindo do facto de ser Havana um fóco intenso e secular da molestia, admittiam a hypothese de ter sido a febre amarella propagada por outro mechanismo que não o mosquito nos casos dos estudos experimentaes.

Foi para arredar essas duvidas, e para poder trilhar firmemente novo caminho no combate á terrivel molestia, que S. Paulo repetiu os estudos experimentaes sobre o assumpto.

Para acompanhar em todo os seus detalhes as memoraveis experiencias realizadas no Hospital de Isolamento desta capital foram convidados es distinctos clinicos drs. L. P. Barreto, Adriano J. de Barros e A. G. da Silva Rodrigues, que apresentaram um excellente relatorio confirmanclo inteiramente as conclusões obtidas em Havana.

Como vemos, o illustre dr. Barreto vem ha muitos annos se impressionando com o nosso estado sanitario, e é por isso que devo pôr em evidencia o seu benefico papel na extincção da molestia que tanto preoccupou a sua intelligente attenção e que infelicitou profundamente o Brasil, entravandothe o progressa por mais de meio seculo.

Ha 11 annos completos cessaram em todo o territorio do Estado de S. Paulo as assoladoras explosões do typho-icteroide, graças á guerra de exterminio aos mosquitos.

Em Sorocaba depois de uma enorme epidemia definida por 2.322 doentes e 877 obitos, nem um só caso de febre amarella se verificou no decorrer dos 14 annos seguintes.

Nesta cidade foi obtida nitidamente a prova epidemiologica, antes de conhecerem em nosso meio os brilhantes resultados a que chegou o general Wood, governador da ilha de Cuba e medico do exercito americano, que empregou para o saneamento daquella ilha os mesmos preceitos postos em acção em Sorocaba e finalmente o mesmo resultado favoravel é alcançado $\epsilon \mathrm{m}$. Ribeirão Preto, onde a observação epiđámiologica é por certo mais in- 
teressante do que a de Havana, por não ser feita nesta cidade paulista renhuma desinfecção nem obras de saneamento, como se extcutaram na capital cubana.

Tendo estado sempre o illustre dr. Barretto na linha da frente nos combates decisivos contra o maior inimigo da nossa civilisação, é de inteira justiça lembrar, e eu o faço com o maximo prazer, no momento das suas festas jubilares, quando the são consagradas as merecidas provas de alto apreço e reconhecimento por todas as nossas classes sociaes, os grandes serviços prestados á causa da saude publica.

(Dos Annaes Paulista de Medicina e Cirurgia)

Laboratorio de Anatomia

FACULDADE DE MEDICINA E CIRURGIA DO ESTADO DE S. PAULO

Director: Prof. A. BOVERO

\title{
VARIEDADES DAS VEIAS DA BASE DO PESCOÇO
}

\author{
OBSERVAÇOES DE RAUL MALHEIROS E A. ARRUDA SAMPAIO \\ ( QUARTO-ANNISTAS)
}

E' facto bem sabido que não constitue novidade encontrarem-se muito frequentemente no systema venoso disposições mais ou menos differentes das descriptas nos tratados classicos; e. precisamente por isso, nem sempre é facil a fixação de um typo constante, eschematico para cada districto do systema venoso. O desappareceimento ou a maior accentuação das disposições habituaes, - pequenas anastomoses, por exemplo - são susceptiveis de originar modalidades que representam uma passagem gradual, por vezes insensivel, entre essas disposições mais communs que se consideram portanto como anormaes, e as muitas outras que podem racionalmente ser descriptas como verdadeiras variedades, ou mesmo constituir de todo o ponto anomalias. As asymetrias frequentes sendo constantes observadas em certos grupos venosos são passiveis, é claro, de interpretação á luz do memo criterio.

Parece-nos digna de interesse a disposiçăo algo anormal das veias da base do pescoço, por nós observadas acidentalmente numa preparação de plexo cervical e merecedora, portanto, de rapida descripção. Convictos de que não apresentam as linhas que seguem modalidades extremamente raras ou novidades, quer-nos parecer, repetimos, que estas notas of ferecem interesse, embora diminuto: constituem um simples relatorio da sala de dissecção, não pretendendo ser uma contribuição ao conhecimento do sys- 